Please do not remove this page

RMIT

UNIVERSITY

\title{
A compact broadband spiral antenna
}

Fu, Wei; Lopez-Lara, Elias; Rowe, Wayne; Ghorbani, Kamran

https://researchrepository.rmit.edu.au/esploro/outputs/9921863785701341/filesAndLinks?institution=61RMIT_INST\&index=null

Fu, W., Lopez-Lara, E., Rowe, W., \& Ghorbani, K. (2008). A compact broadband spiral antenna. Proceedings Fro the 2008 Asia-Pacific Microwave Conference, 1-4. https://doi.org/10.1109/APMC.2008.4958167

Document Version: Published Version

Published Version: https://doi.org/10.1109/APMC.2008.4958167

Repository homepage: https://researchrepository.rmit.edu.au

(c) Copyright 2009 IEEE. Personal use of this material is permitted. However, permission to reprint/republish this material for advertising or promotional purposes or for creating new collective works for resale or redistribution to servers or lists, or to reuse any copyrighted component of this work in other works must be obtained from the IEEE.

Downloaded On 2023/04/26 21:18:17 +1000 


\title{
A Compact Broadband Spiral Antenna
}

\author{
Wei Fu' ${ }^{1}$, Elias R. Lopez, Wayne S.T. Rowe, Kamran Ghorbani \\ School of Electrical and Computer Engineering, RMIT University, Australia \\ ${ }^{1}$ S3089134@student.rmit.edu.au
}

\section{Introduction}

As a member of frequency-independent antennas, a spiral antenna has salient features like ultra wide impedance bandwidth, radiating circular polarized EM wave and very wide radiation beam. It is straightforward to design a spiral antenna which works in free space over a 1:20 bandwidth. However many applications require antenna radiating unidirectionally as well as having low volume. Spiral antennas backed by a lossy cavity $[1,2]$ had solved the problem of bidirectional radiation but the cavity added extra depth and weight to the antenna system. Later cavity was made thinner $[3,5]$ and the gain was improved by using stepped cavity [4]. However some applications require the antenna system to be extremely compact or reject the usage of microwave absorbing material. The approach of employing chip resistors in a microstrip spiral antenna structure [6] is a very good option for these applications. In our previous work [7] a single arm equiangular spiral antenna with embedded chip resistors was developed to achieve 9:1 impedance bandwidth. Also the dual arm spiral antenna with chip resistors was designed. However the antenna size was an issue due to use of the vertical balun. In order to reduce the size of the spiral antenna, a compact balun is developed which can be integrated into the spiral antenna. This paper presents a dual arm equiangular spiral antenna with embedded chip resistors and a compact balun. Section II explains the configuration of the entire antenna structure. Section III presents the simulated results including $\mathrm{S}_{11}$, gain, radiation patterns and relevant discussion.

\section{Configuration of Antenna}

In this design, the dual arm equiangular spiral antenna is etched on the grounded dielectric substrate with several chip resistors inside the substrate connecting the arms to the ground plane. Figure 1 (L) shows the dual arm equiangular spiral antenna with chip resistors and embedded balun. It is made of two layers of Duroid 5880 with different thicknesses. The spiral is etched on the thin layer which is $0.508 \mathrm{~mm}$. The thick layer, which is $3.175 \mathrm{~mm}$ with a ground plane, has a slot where the balun is placed horizontally with both output pairs connected to both arms of the spiral antenna.

The curves which form one arm of a planar equiangular spiral antenna are expressed as:

$\rho_{1}=\rho_{0} e^{a\left(\phi-\phi_{0}\right)} \quad \phi_{0} \leq \phi \leq \phi_{e d}$

$\rho_{2}=\rho_{0} e^{a\left(\phi-\phi_{0}-\delta\right)} \quad \phi_{0} \leq \phi \leq \phi_{e d}+\delta$

$\rho_{1}, \rho_{2}$ are radial length at curve 1 and curve 2 at rotation angle $\phi, \phi$ is the expansion angle which starts from $\phi_{0}$ and ends with $\phi_{\text {ed }}$. All the structural parameters referred in (1) of this antenna are $\mathrm{a}=0.35, \delta=0.5 \pi, \phi_{0}=0.67 \pi, \phi_{\text {ed }}=3.7 \pi$ and $\rho_{0}=0.508 \mathrm{~mm}$. The other arm could be obtained by duplicating this arm along the normal axis with $180^{\circ}$ rotation.

Compared to the single arm spiral in previous work, this dual arm spiral antenna has symmetric radiation pattern and better axial ratio, however it requires a balanced feeding network with characteristic impedance of $120 \Omega$. Therefore a balun is required to not only change unbalanced source into balanced sources but also to transform characteristic impedance from $50 \Omega$ to $120 \Omega$. It is well known that in the design of spirals backed by cavities the tapered baluns are placed inside the cavity, which does not add extra size to the 
antenna system. But for a microstrip spiral antenna there is no space to conceal a long tapered balun. In order to solve this problem, a new balun, similar to [8], was developed to be horizontally embedded inside the substrate. As seen in Figure1(R) this balun is formed by the two parallel lines etched on both sides of the thin dielectric slab which is $62.2 \mathrm{~mm}$ long, 2.39 $\mathrm{mm}$ wide and $0.508 \mathrm{~mm}$ thick with $\varepsilon_{\mathrm{r}}=3.38$. The balun connects the coaxial connector with impedance of $50 \Omega$ to the balanced feed spiral output with odd mode impedance of $120 \Omega$.

\section{Simulation results and discussion}

This dual arm equiangular spiral antenna with the embedded balun and embedded chip resistors is simulated using Ansoft HFSS v10.1.3. Figure 2 shows the simulated VSWR of the spiral antenna. From Figure 2, it can be seen that this antenna has a VSWR of less than 2 over most of the frequency range from $2-18 \mathrm{GHz}$.

Figure 3 shows normalized simulated radiation pattern of far zone total Electric field magnitude (dB) at $2 \mathrm{GHz}(\mathrm{a}), 10 \mathrm{GHz}(\mathrm{b})$ and $18 \mathrm{GHz}(\mathrm{c})$. From Figure 3 it can be observed that there are a few issues with the radiation patterns:

1. There are ripples at high frequencies.

2. The radiation pattern is not symmetric at high frequencies $(\geq 10 \mathrm{GHz})$ and the main lobe has evident tilt from the normal axis.

For the first issue, the main reason is a surface wave is generated which diffracts at the edge of the substrate and contributes to far field radiation. Surface waves are generally excited at high frequencies on grounded substrates, so that it does not greatly affect radiation pattern at low frequencies.

Figure 4 shows the comparison of radiation patterns of the spiral with and without balun at 2 $\mathrm{GHz}$ and $18 \mathrm{GHz}$ respectively. It can be seen how much the embedded balun affects the radiation patterns of the spiral antenna. From Figure 4(a) it is obvious at $2 \mathrm{GHz}$ within the theta range of interests $\left(-90^{\circ}-90^{\circ}\right)$ the balun has little affect on the far field radiation. Similarly in Figure 4(c) the two lines are very close which means the balun does not affect the radiation of the spiral at $18 \mathrm{GHz}$. However at $18 \mathrm{GHz}$ the radiation beam dramatically tilts in Figure 4(b). This is the plane in which the planar balun is located. This is the reason for the second issue mentioned above, e.g., the asymmetric of radiation pattern and the tilt of main lobe are mainly caused by the effect of the embedded balun.

Figure 5 shows the simulated gain of this spiral with compact balun versus a commercial Archimedean spiral antenna backed by a microwave absorber stuffed cavity. It can be seen that over low the frequency range $(2-6 \mathrm{GHz})$ this designed spiral has lower gain than that of the commercial antenna. However at the higher frequency range the gain maintains a similar range to the commercial antenna. Its advantage of being compact and light would make it competitive if low volume is required. The measured $\mathrm{S}_{11}$, gain, radiation patterns will be presented at meeting.

Acknowledgements: The work is supported by Australian Research Council. Also the authors would like to acknowledge the valuable assistance of Dr James Scott. 


\section{References}

[1] J. Dyson, "The unidirectional equiangular spiral antenna", IEEE Trans. on Antennas and Propagation, vol. 7, no. 4, pp. 329-334, 1959.

[2] T. E. Morgan, "Reduced Size Spiral Antenna", European Microwave Conference, pp.181-185, Oct. 1979.

[3] J. J. H. Wang and V. K. Tripp, "Design of Multioctave Spiral-mode Microstrip Antennas", IEEE Transactions on Antennas and Propagation, vol. 39, no. 3, pp. 332335, 1991.

[4] M. N. Afsar, Yong Wang and D. Hanyi, "A new wideband cavity-backed spiral antenna", IEEE Antennas and Propagation Society International Symposium, vol. 4, pp. 124 - 127, July 2001.

[5] J. L.Volakis, M. W. Nurnberger and D. S. Filipovic, "A broadband cavity-backed slot spiral antenna", IEEE Trans. Antennas and Propagation, vol. 43, no. 6, 2001.

[6] L. Schreider, X. Begaud, M. Soiron and B. Perpere, "Archimedean microstrip spiral antenna loaded by chip resistors inside substrate", IEEE Antennas and Propagation Society International Symposium, vol. 1, pp. 1066-1069, 2004.

[7] W. Fu, E. R. Lopez, J. Scott, W. S. T. Rowe and K. Ghorbani, "Broadband equiangular spiral antenna with embedded chip resistors", Asia-Pacific Microwave Conference (APMC 2007), pp. $1-4$, Dec. 2007.

[8] P. Salem, C. Wu and M. C. E Yagoub, "Novel ultra wideband printed balun design using the FEM and FDTD methods", IEEE Antennas and Propagation Society International Symposium, vol. 2A, pp. 643 - 646, July 2005.

Figures

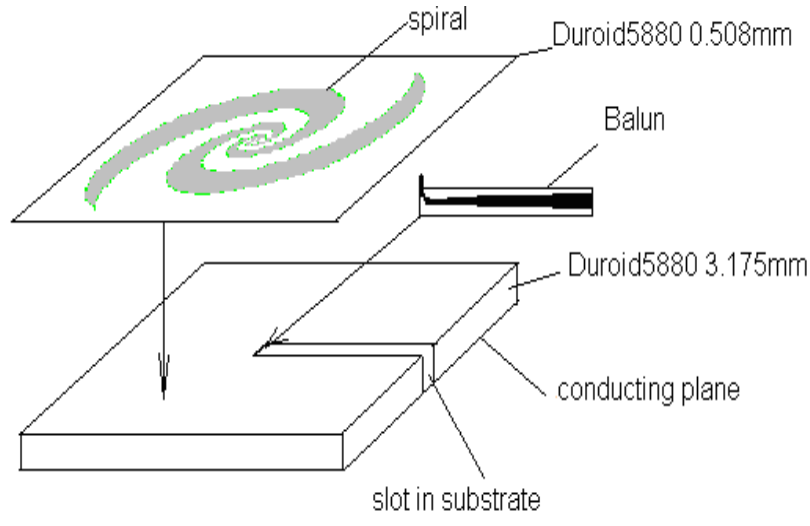

(L)

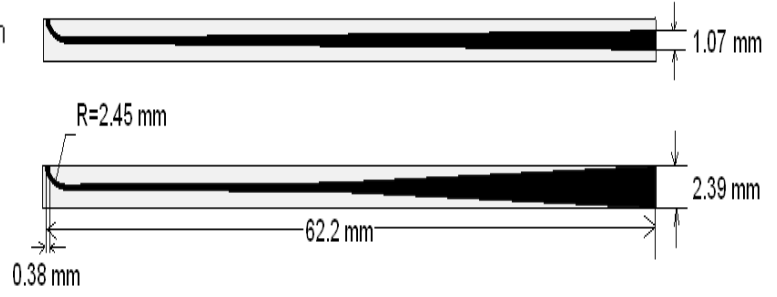

(R)

Figure 1. The antenna system $(\mathrm{L})$ configuration of system $(\mathrm{R})$ profile of balun

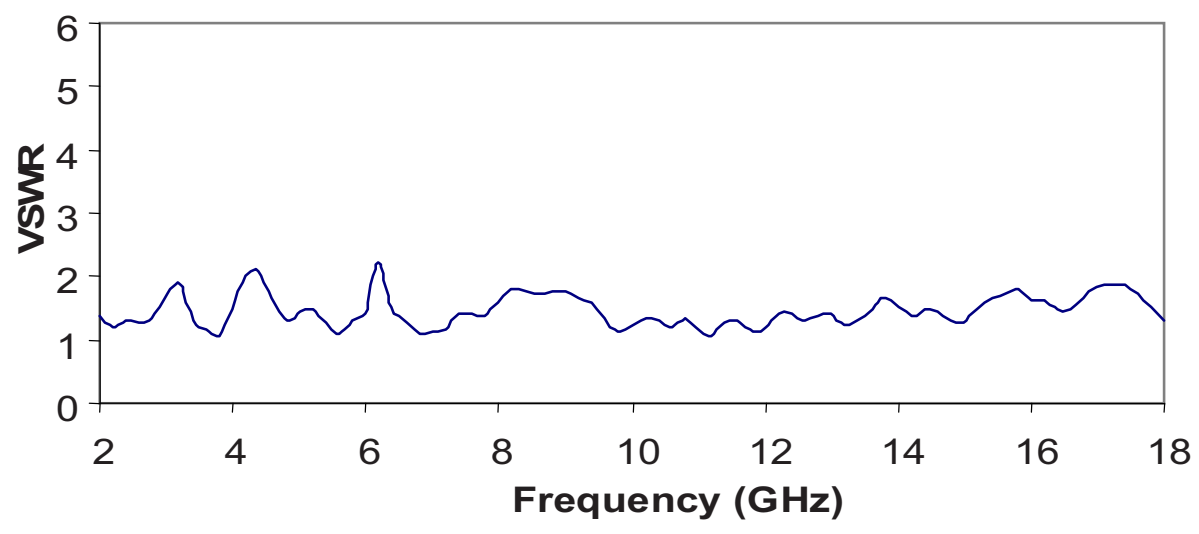


Figure 2. The simulated VSWR of the antenna with balun and chip resistors

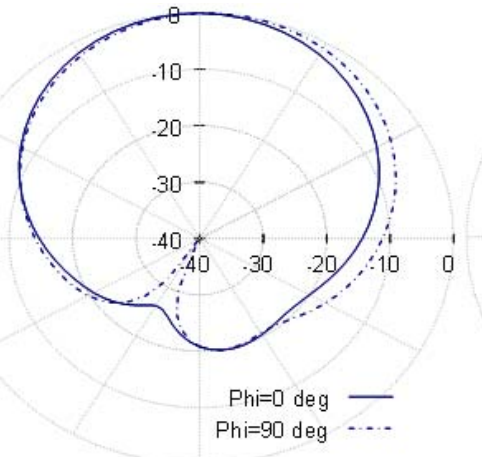

(a) $2 \mathrm{GHz}$

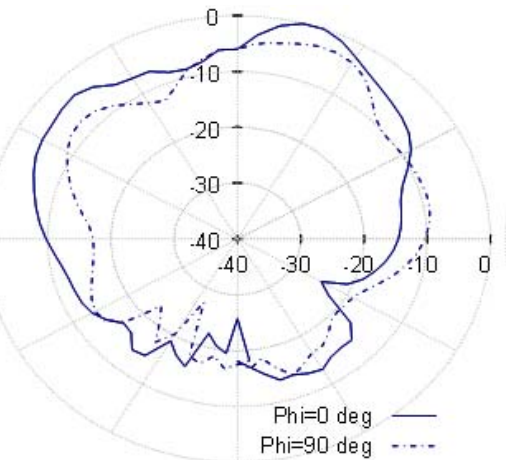

(b) $10 \mathrm{GHz}$

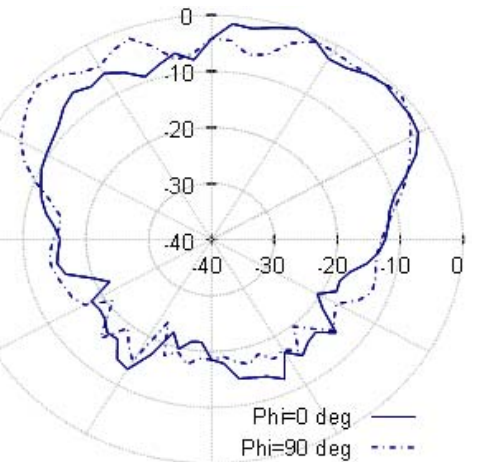

(c) $18 \mathrm{GHz}$

Figure 3. The normalized simulated far zone $\mathrm{E}$ total $(\mathrm{dB})$ of the antenna with balun.
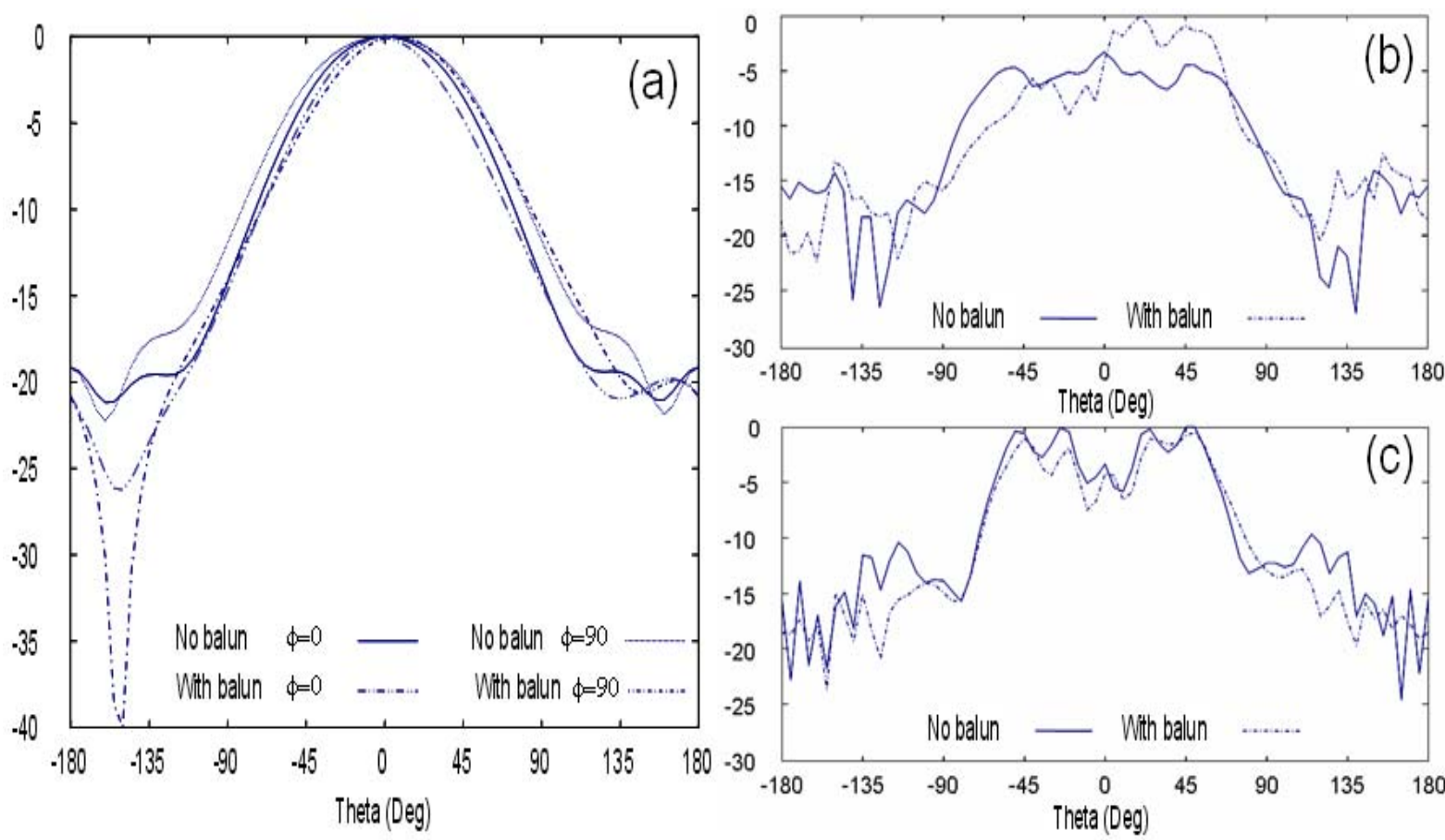

Figure 4. The effect of the balun on the radiation patterns (normalized far zone total $\mathrm{E}$ magnitude (dB)) (a) $2 \mathrm{GHz}(b) 18 \mathrm{GHz} \phi=0^{\circ}$ (c) $18 \mathrm{GHz} \phi=90^{\circ}$

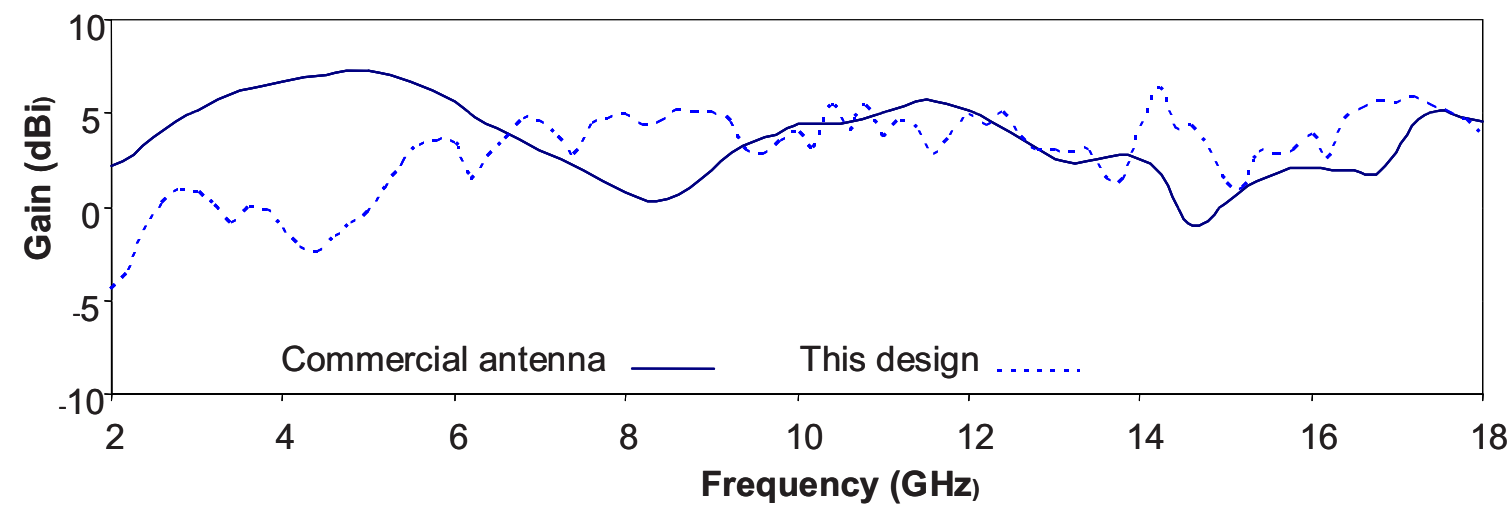

Figure 5. The simulated gain of the proposed spiral and the gain of a commercial spiral antenna backed by an absorbing cavity. 